\title{
Editorial: The Civic and Political Participation of Young People: Current Changes and Educational Consequences
}

\author{
Pedro D. Ferreira ${ }^{1 *}$ and Isabel Menezes ${ }^{1 *}$ \\ ${ }^{1}$ CIIE-Center for Educational Research and Intervention, Faculty of Psychology and Education Sciences, University of Porto, \\ Porto, Portugal
}

Keywords: participation, young people, education, political, civic engagement, political development

\section{Editorial on the Research Topic}

The Civic and Political Participation of Young People: Current Changes and Educational Consequences

Academic concern with political participation is now well established, and research on the participation of young people has been expanding. Fueling this growth is both the recognition of a preoccupying trend-young people are disengaging from more traditional and institutional forms of participation - and of their strong presence and influence in movements that are led by or largely made up of young people-e.g., the March for Our Lives in the United States, the Fridays For Future, first in Europe and then globally, or the Hong Kong democracy movement. This double recognition and its tensions has been challenging the field to look again at educational institutions and to how they contribute to the political education of youth, and to understand how new possibilities, new foci and new repertoires have been transforming the ways young people understand political action, and themselves as political actors.

In What Is Youth Political Participation? Literature Review on Youth Political Participation and Political Attitudes, Weiss takes a close look at the literature on youth political participation in contemporary Europe. Interestingly she concludes that existing definitions of political participation can be used to capture the political participation of young people, but she finds them falling short in accounting for new modes of participation that are common among young people (e.g., online or expressive) and in paying adequate attention to non-participation. After reviewing the differences between the political participation of adults and young people, she also emphasizes the need to further the research on youth-specific definitions, explanations and measurements. This is taken one step further by Biswas in her paper Letting Teach: Gen Z as Socio-Political Educators in an Overheated World. Taking a childist stance, she makes the case for a reconfiguration of socio-political education where the roles of children and young people go beyond being taught, that acknowledges the contributions of children and young people to political participation and to how it can be understood, and learns from them. Recognizing how Gen $\mathrm{Z}$ has been exploring the possibilities of large scale connective action in movements such as \#FridaysforFuture which simultaneously resist adultist positions, bring things to say into the intergenerational dialogue about the future, and challenge the minor political role of "minors". Education institutions can play an important role in this by valuing, fostering and recognizing how students are engaging with pressing social topics within and beyond the school, and transforming citizenship and political education to become part of an intergenerational relationship where adults can teach but also learn with and from children. 
Concerns about how schools provide (or not) the opportunities and experiences for students to develop as active and critical citizens are at the center of the work by Tzankova et al., Perceived School Characteristics Fostering Civic Engagement Among Adolescents in Italy. Following a mixed methods approach, the authors explore how school aspects and experiences such as democratic school climate and student participation affect students' civic attitudes and behaviors. Results show that student participation (in student councils, groups or clubs) and political interest have an effect on civic participation, and students recognize the formative value of debates and confrontation of opinions as well of participating in school councils and assemblies in fostering interest in social issues, but they also say that teachers often avoid debate on topic issues in the classroom for fear of conflict, and that school authorities are frequently unresponsive to student voices. Interestingly, these results also point to the importance of participative environments (in and out of school), where young people can engage with issues they value, that invite critical reflection, where they can contribute and effect change. Schools and educators can play a role in promoting, supporting, and nurturing these kinds of environments and experiences, which play a significant role in the political education of young people.

Getting involved in Fridays for Future can be one such experiences, and that is explored by Parth et al. in "How Dare You!"-The Influence of Fridays for Future on the Political Attitudes of Young Adults. The authors consider political attitudes to be influenced by experiences of political participation, and by socialization institutions like schools or the family and friends. Protest experience (for those who had been primed for Fridays for Future) increased satisfaction with democracy, and so did the experience of equal treatment in school. This reinforces the need to pay closer attention to the socializing power of a diversity of contexts, from school aspects to political and social movements, to understand how political attitudes of young people are transformed. Reichert's paper Collective Protest and Expressive Action Among University Students in Hong Kong: Associations Between Offline and Online Forms of Political Participation looks at the mobilizations in Hong Kong, specifically at the online and offline political participation of young adults shortly before the mobilizations of 2019 and 1 year later. Online participation rates were higher, and it appeared to reach more those groups who may have more obstacles to participating offline (e.g., women). Taking advantage of the longitudinal design it shows that, although online and offline participation is positively related, and participating in one mode increased the probability of participating in the other, strong support was found to the importance of offline political participation experiences in increasing both online and offline participation.

Papers in this Research Topic highlight the importance of studying the political participation of young people in their own terms, and in contexts that are particularly significant for them. The political subjectivation of young people is happening online and offline, in various movements where they act and contribute to change and to a future. This involvement matters and if schools should definitely recognize, nurture and support opportunities for youth involvement and learn from them, scholarship should also avoid looking at them as not-yet-adults. If they are becoming political, isn't everybody, despite their age?

\section{AUTHOR CONTRIBUTIONS}

All authors listed have made a substantial, direct, and intellectual contribution to the work and approved it for publication.

Conflict of Interest: The authors declare that the research was conducted in the absence of any commercial or financial relationships that could be construed as a potential conflict of interest.

Publisher's Note: All claims expressed in this article are solely those of the authors and do not necessarily represent those of their affiliated organizations, or those of the publisher, the editors and the reviewers. Any product that may be evaluated in this article, or claim that may be made by its manufacturer, is not guaranteed or endorsed by the publisher.

Copyright (c) 2021 Ferreira and Menezes. This is an open-access article distributed under the terms of the Creative Commons Attribution License (CC BY). The use, distribution or reproduction in other forums is permitted, provided the original author(s) and the copyright owner(s) are credited and that the original publication in this journal is cited, in accordance with accepted academic practice. No use, distribution or reproduction is permitted which does not comply with these terms. 